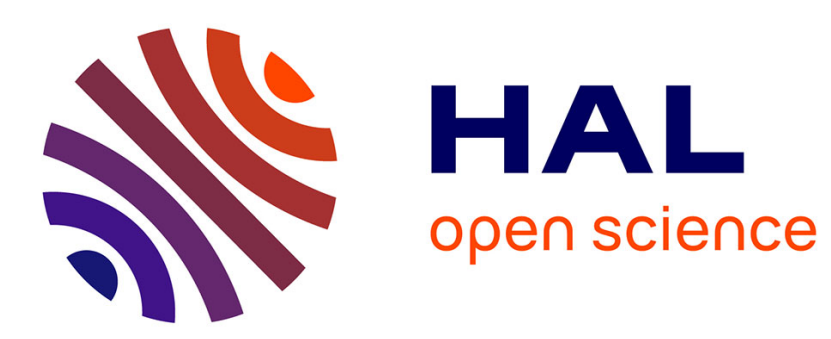

\title{
Kinetics of Liquid/Liquid Extraction of Europium(III) Cation by Two Malonic Diamides
}

\author{
Jean-Pierre Simonin, Laurent Perrigaud, Katy Perrigaud, Trong-Hung Vu
}

\section{To cite this version:}

Jean-Pierre Simonin, Laurent Perrigaud, Katy Perrigaud, Trong-Hung Vu. Kinetics of Liquid/Liquid Extraction of Europium(III) Cation by Two Malonic Diamides. Solvent Extraction and Ion Exchange, 2014, 32 (4), pp.365-377. 10.1080/07366299.2013.866849 . hal-01310910

\section{HAL Id: hal-01310910 https://hal.sorbonne-universite.fr/hal-01310910}

Submitted on 3 May 2016

HAL is a multi-disciplinary open access archive for the deposit and dissemination of scientific research documents, whether they are published or not. The documents may come from teaching and research institutions in France or abroad, or from public or private research centers.
L'archive ouverte pluridisciplinaire HAL, est destinée au dépôt et à la diffusion de documents scientifiques de niveau recherche, publiés ou non, émanant des établissements d'enseignement et de recherche français ou étrangers, des laboratoires publics ou privés. 


\title{
Kinetics of Liquid/Liquid Extraction of Europium(III) Cation by Two Malonic Diamides
}

\author{
Jean-Pierre Simonin* , Laurent Perrigaud ${ }^{\dagger}$, Katy Perrigaud $^{\ddagger}$, \\ and Trong-Hung $\mathrm{Vu}^{\S}$
}

Laboratoire PECSA (UMR CNRS 7195), Université P.M. Curie, Case 51, 4 Place Jussieu, 75252 Paris Cedex 05, France

\begin{abstract}
In the framework of the DIAMEX separation process, the kinetics of extraction of Eu(III) ion by two diamides, DMDBTDMA and DMDOHEMA, have been studied using the rotating membrane cell technique. The kinetics with DMDBTDMA from a nitric acid solution were found to be very fast, in keeping with a previous work using the Nitsch cell, and in disagreement with another work using a Lewis-type cell. A simple model for turbulent transport in the latter cell is proposed to interpret this result. The extraction kinetics with DMDOHEMA were found to be slower than with DMDBTDMA at $22^{\circ} \mathrm{C}$. The activation energy of the interfacial reaction was deduced from experiments at $11^{\circ} \mathrm{C}, 22^{\circ} \mathrm{C}$ and $33^{\circ} \mathrm{C}$. The activation energy of the distribution ratio is shown to have a particular effect on that of the overall kinetic rate constant in the general case.
\end{abstract}

Keywords: Kinetics, extraction, diamide, europium ion, DIAMEX.

\footnotetext{
*Corresponding author: jpsimonin@gmail.com

'Present address: Laboratoire GIP ARRONAX, 1 rue Aronnax, CS 10112, 44817 Saint-Herblain Cedex, France.

"Present address: Laboratoire Subatech (UMR CNRS 6457), EMN, BP 20722, 4 rue Alfred Kastler, 44307 Nantes cedex 3, France.

${ }^{\S}$ Present address: ICMUB, Université de Bourgogne, UFR Sciences et Techniques, Faculté des Sciences Mirande, Aile B, 9 avenue Alain Savary, BP 47870, 21078 Dijon Cedex, France.
} 


\section{INTRODUCTION}

Malonic acid diamides have been selected as a class of extractants for the DIAMEX process, ${ }^{[1-3]}$ which consists of the selective co-extraction of minor actinides (americium and curium) and fission lanthanides from nuclear wastes in the reprocessing of nuclear spent fuel. Besides being good extractants, these compounds have the interesting property of being composed of $\mathrm{C}, \mathrm{H}, \mathrm{O}$ and $\mathrm{N}$ atoms, which makes them good candidates for incineration. Moreover, they exhibit good resistance to radiolysis.

Two diamides have been studied in particular for applications in the nuclear reprocessing industry, in the DIAMEX-SANEX process ${ }^{[4]}$ : the N,N'-dimethyl-N,N'-dibutyl-tetradecyl malonic diamide (DMDBTDMA) and, preferentially, the N,N'-dimethyl-N,N'-dioctyl-2-(2hexyloxy-ethyl) malonic diamide (DMDOHEMA). This process allows the trivalent actinides and lanthanides to be co-extracted and separated in a single liquid-liquid extraction cycle. The extracting solvent (diamide + diluent) is generally supplemented by an acidic extractant, the diethylhexylphosphoric acid (HDEHP), to ensure effective extraction at the $\mathrm{pH}$ used in the process.

The kinetics of transfer by these solvents is therefore an important parameter for the design of extractors at industrial scale. However it has not been studied extensively in the literature. This fundamental topic has been investigated by Toulemonde, ${ }^{[5]}$ Dal Don, ${ }^{[6]}$ Charbonnel et al., ${ }^{[7]}$ Weigl et al. ${ }^{[8]}$ in the case of DMDBTDMA, and by Bosland ${ }^{[9]}$ in the case of DMDOHEMA.

The extractant DMDOHEMA has also been used in conjunction with other extracting molecules, such as the HDEHP in the DIAMEX-SANEX process, and the CyMe${ }_{4}$-BTBP molecule $^{[10]} \quad\left(6,6^{\prime}\right.$-Bis(5,5,8,8-tetramethyl-5,6,7,8-tetrahydrobenzo-1,2,4-triazin-3-yl)-2,2'bipyridine) as a phase transfer catalyst because of slow kinetics with the BTBP.

One of the main issues in the field of extraction kinetics is the control, or at least the minimization, of the diffusive contribution to the overall process. ${ }^{[1-13]}$ In refs. [5-7] the kinetics were studied using a Lewis-type cell. It was recognized by Danesi ${ }^{[14]}$ that this technique is characterized by poorly defined hydrodynamics and ultimate film thicknesses of the order of $10 \mu \mathrm{m}$. The plateau observed for the velocity of transfer as a function of the rotation speed of the propellers, which is generally attributed to a kinetic regime, can be 
misleading. In fact, it can result from a 'slip effect' of the fluids on the blades of the propellers when their rotation speed is increased above some critical speed, ${ }^{[14]}$ not from a kinetic regime in which the contribution from diffusive transport has been minimized. In contrast, the cell used by Weigl et al. ${ }^{[8]}$ is more reliable because it was devised by W. Nitsch in an effort to overcome the deficiencies of the Lewis cell. It possesses a more efficient stirring, capable of identifying the nature of the regime more reliably. Let us note that the cell was tested with systems operating in diffusional regime. ${ }^{[8]}$

In the case of the kinetics of extraction of Eu(III) with the diamide DMDBTDMA, the workers using the Lewis-type cell concluded that the transfer was controlled by a slow interfacial chemical reaction. ${ }^{[6,7]}$ On the other hand, the use of the Nitsch cell by Weigl et al. pointed to a diffusion controlled process. ${ }^{[8]}$ In view of these two opposite conclusions, it seemed desirable to further study this system with the use of a different technique in order to resolve the issue of the extraction regime.

In this work, the rotating membrane cell (RMC) technique is employed for this purpose. A first approach for the estimation of diffusive transport in a Lewis-type cell as used in refs. [57] is proposed. This simple model may give insight into the discrepancy between the results of refs. [6,7] and those of ref. [8]. Moreover, the extraction kinetics of $\mathrm{Eu}(\mathrm{III})$ by DMDOHEMA are studied using the RMC at different temperatures. The activation energies of the various relevant parameters involved in the overall extraction process are measured and their influence is discussed.

The next section presents the model for the transfer of solute in a Lewis-type cell. Then, the RMC technique is briefly described in the third section. The results for the kinetics of extraction of Eu(III) by DMDBTDMA and DMDOHEMA are given in the fourth section. Finally, concluding remarks and prospects are presented in the conclusion section.

\section{MODEL FOR DIFFUSIVE TRANSPORT IN A LEWIS-TYPE CELL}

We consider a Lewis-type cell, which consists of two immiscible liquid phases in contact that are stirred independently by stirring bars or propellers. These stirrers produce a turbulent hydrodynamic flow in the cell, which results in hydrodynamic boundary layers, and diffusion layers for the extracted solute, in the vicinity of the interface. The thickness of these layers 
may be assessed approximately by using the classic theory of turbulence, as presented for instance in the book by Levich. ${ }^{[15]}$

This derivation may be made as follows in the present case. Agitation produces turbulence eddies of various scales in the cell. Let us denote by $V_{0}$ the characteristic velocity of the largest scale eddies in one of the phases. The order of magnitude of the hydrodynamic boundary layer thickness is then given by (Eq. (4.16) of ref. [15]),

$$
\delta_{H} \approx \frac{v}{V_{0}}
$$

in which $v$ is the kinematic viscosity of the liquid. This thickness corresponds to the distance from the interface at which the Reynolds number of the flow near the interface ( $\operatorname{Re}=V \delta / \mathrm{v}$, with $V$ the average velocity of the fluid at a distance $\delta$ from the interface) is approximately equal to unity. At this distance the flow still has a characteristic velocity $V_{0}$ but starts to be significantly damped by viscosity effects in the vicinity of the interface. Eq. (1) expresses the thickness of the 'viscous sublayer'. ${ }^{[15]}$

It may be underlined, in passing, that, in many works reporting experiments carried out with this kind of cell, the Reynolds number for the stream taken as a whole has been expressed as, $\operatorname{Re}_{0} \equiv \omega a^{2} / \nu$, with $\omega$ the rotation speed and $a$ the radius or diameter of the stirrer. This formula is irrelevant because it is does not characterize the flow in the cell. The rotation speed of the propeller or stirrer is not a good indication of the flow, in particular because of the slip effect mentioned above. This Reynolds number must instead be evaluated from a direct experimental measurement of the actual velocity of the fluid.

According to the Landau and Levich hypothesis of gradual damping of turbulence in the viscous sublayer, the thickness of the diffusion layer is approximately given by Eq. (25.18) of ref. [15],

$$
\delta_{D} \approx \alpha \frac{\delta_{H}}{S c^{1 / 4}}
$$

with Sc the dimensionless Schmidt number, $\mathrm{Sc} \equiv \mathrm{v} / D, D$ the diffusion coefficient of the solute in the phase considered, and $\alpha$ a parameter of the order of unity.

The kinetic rate constant for diffusion in a given phase is, ${ }^{[13]}$ 


$$
k_{D}=\frac{D}{\delta_{D}}
$$

from which one gets using Eqs. (1) and (2),

$$
k_{D}=\alpha^{-1} V_{0} S c^{-3 / 4}
$$

For an extraction experiment, the total resistance to transfer due to diffusive transport is, ${ }^{[13]}$

$$
R_{D} \equiv \frac{1}{k_{D}^{e x t r}}=\frac{1}{k_{D}^{a q}}+\frac{1}{K k_{D}^{\text {org }}}
$$

in which $K$ is the distribution ratio $\left(=C_{o r g} / C_{a q}\right)$, the superscript $a q$ stands for aqueous phase, org for organic phase, and extr for extraction.

\section{THE RMC TECHNIQUE}

\section{Description}

A sketch of the technique is shown in Figure 1. The cell consists of a thin membrane that is glued on the base of a cylinder made of perspex. The membrane is a hydrophilic HVLP Durapore filter purchased from Millipore $^{\mathrm{TM}}$ (thickness $\approx 120 \mu \mathrm{m}$, diameter of ca. $8 \mathrm{~mm}$ ). It is impregnated with the aqueous phase in the present work. However, the organic phase can also be placed in the membrane provided a suitable type of filter is used. ${ }^{[16]}$ This phase, denoted by A, is spiked with the radioactive tracer to be extracted. The cell is mounted on a rotatingelectrode spindle that can be rotated at a definite speed. Initially, it is set into rotation at a known speed and it is immersed into the outer phase B.

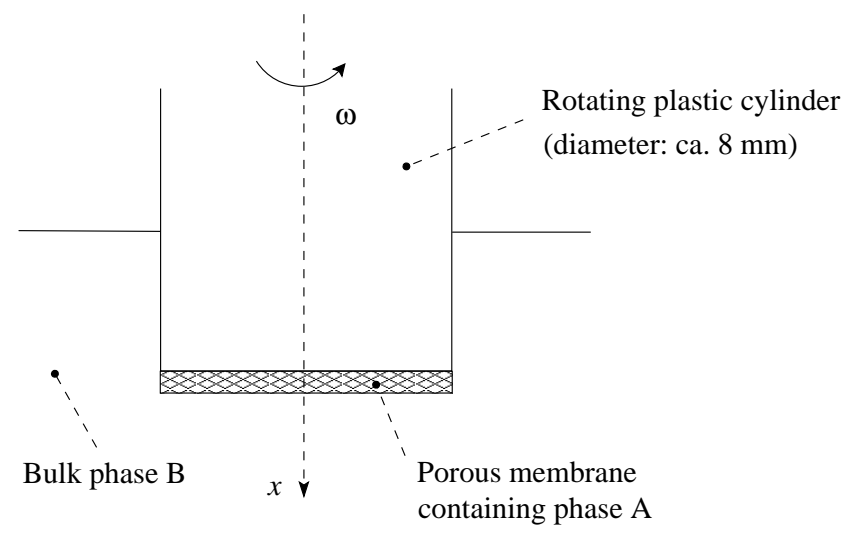

Figure 1. Sketch of the RMC technique. The membrane, impregnated with one of the phases, is glued on the basis of a rotating cylinder made of perspex (see text). 
The main feature of the RMC is that transport is controlled in both phases. In phase A, transport in the pores of the membrane is purely diffusive. It obeys the classic Fick's law with an effective diffusion coefficient accounting for tortuosity of the membrane. In phase B, rotating-disc hydrodynamics is promoted, which creates a convective transport process in that phase. The latter can be described following the theory of Levich. ${ }^{[15]}$ The determination of the contributions from transport in phases $\mathrm{A}$ and $\mathrm{B}$ requires the measurement the diffusion coefficients of solute in the two phases. They were determined using the closed capillary technique. ${ }^{[17]}$ Formally, the diffusive contributions may be subtracted from the overall process, thus yielding the contribution from interfacial transfer alone.

\section{Main formulas}

The proportion of matter extracted during an interval of time $t$ reads, ${ }^{[18,19]}$

$$
P(t)=1-\exp (-t / \tau)
$$

where $\tau$ is the average transfer time of the solute from the bulk of A to the bulk of $B$. It is given by

$$
\tau=\tau_{A}+\tau_{\chi}+\tau_{B}
$$

in which $\tau_{\mathrm{A}}$ is the mean diffusion time of solute in phase $\mathrm{A}$ (in the membrane), $\tau_{\chi}$ is the characteristic time for the A-to-B interfacial chemical reaction, and $\tau_{\mathrm{B}}$ is the mean diffusion time of solute in the diffusion layer in $\mathrm{B}$, which results from the competition between backextraction and removal from the interfacial region into the bulk of B. One has,

$$
\tau_{\chi}=\frac{L}{k_{f}} \quad \tau_{A}=\frac{L^{2}}{3 D_{m}} \quad \tau_{B}=\frac{\sigma L \delta_{B}}{K D_{B}}
$$

in which $k_{f}$ is the forward kinetic rate constant (from A to B), $L$ is the membrane thickness, $D_{\mathrm{m}}$ and $D_{\mathrm{B}}$ are the solute diffusion coefficients in the membrane and in B, respectively, $\sigma$ is the membrane porosity, and $\delta_{\mathrm{B}}$ is the diffusion layer thickness in phase $\mathrm{B}$ (its value being given by the Levich equation ${ }^{[15]}$ ). The diffusion coefficient in the membrane is given by $D_{\mathrm{m}}=$ $D_{\mathrm{A}} / f$, with $f$ the tortuosity of the membrane. The distribution ratio satisfies the relation

$$
K=\frac{k_{f}}{k_{r}}
$$


with $k_{\mathrm{r}}$ the kinetic rate constant for the reverse $\mathrm{B}$-to-A chemical reaction. Thus, if $\mathrm{A}$ is aqueous and $\mathrm{B}$ is organic, then $k_{\mathrm{f}}$ is the extraction rate constant and $k_{\mathrm{r}}$ is the back-extraction rate constant.

Eq. (7) may be rewritten in the following different form,

$$
k^{-1}=k_{A}^{-1}+k_{f}^{-1}+\left(K k_{B}\right)^{-1}
$$

with $k \equiv L / \tau$ the global apparent rate constant, and $k_{\mathrm{A}} \equiv L / \tau_{\mathrm{A}}=3 D_{\mathrm{m}} / L$ and $k_{\mathrm{B}} \equiv L / \tau_{\mathrm{B}}=D_{\mathrm{B}} / \sigma \delta_{\mathrm{B}}$, the equivalent kinetic rate constants for diffusive transport in $\mathrm{A}$ and $\mathrm{B}$, respectively. This relation has the same form as the classical A-to-B apparent rate constant in a stirred cell operating in a stationary regime. ${ }^{[13,14]}$ It expresses the additivity of the resistances to mass transfer.

In the case of infinitely fast interfacial kinetics ( $\mathrm{k}_{\mathrm{f}}$ and $\mathrm{k}_{\mathrm{r}} \rightarrow \infty$ with $K$ unchanged), the process becomes diffusion controlled and Eq. (2) reduces to

$$
\tau_{\infty}=\tau_{A}+\tau_{B}
$$

Replacing $\tau$ by $\tau_{\infty}$ in Eq. (6) yields the diffusive limit, $P_{\infty}$, of the process.

Eq. (6) may be rewritten as

$$
-\ln [1-P(t)]=\frac{t}{\tau}
$$

According to this equation, the experimental points are expected to be located on a straight line of slope $1 / \tau$. A fit of the experimental results yields the time $\tau$. Then, the value of $\tau$ leads to the value of the only unknown parameter $k_{f}$ by virtue of Eqs. (7)-(9) when all the other parameters $(\sigma, L, \ldots)$ have been measured experimentally.

\section{Activation energy}

The activation energy of the global kinetic rate constant $k$ may be calculated from the equation

$$
E_{k}=-\frac{\partial \ln k}{\partial(1 / T)}=\frac{\partial \ln k^{-1}}{\partial(1 / T)}=k \frac{\partial k^{-1}}{\partial(1 / T)}
$$


Thus, if every activated quantity, $X=D_{\mathrm{aq}}, D_{\mathrm{org}}, v_{\mathrm{org}}$ and $K$, in Eq. (10) is written as $X=X_{0} \exp [-$ $\left.E_{\mathrm{X}} / R\left(1 / T-1 / T_{0}\right)\right]$ with $T_{0}$ the reference temperature at which $X=X_{0}$, then after some simple algebra one finds from Eqs. (10) and (13) (evaluated at $T=T_{0}$ ) that,

$$
E_{k}=\frac{\tau_{A}}{\tau} E_{D a q}+\frac{\tau_{f}}{\tau} E_{k f}+\frac{\tau_{B}}{\tau}\left(\frac{2}{3} E_{\text {Dorg }}-\frac{1}{6} E_{\text {vorg }}+E_{K}\right)
$$

We note that, in this relation, all contributions are expected to be positive ( $E_{\text {vorg }}<0$ because viscosities decrease with $T$ ), except for $E_{\mathrm{K}}$ which can be positive or negative. Eq. (9) also implies that $E_{K}=E_{k f}-E_{k r}$.

It is worth mentioning moreover that Eq. (10) provides a decomposition that is valid in the case of techniques in which the phases are stirred. ${ }^{[13,14]}$ Then it stems from Eq. (13) that,

$$
E_{k}=\frac{k_{A}^{-1}}{k^{-1}}\left[\frac{\partial \ln k_{A}^{-1}}{\partial(1 / T)}\right]+\frac{k_{f}^{-1}}{k^{-1}}\left[E_{k f}\right]+\frac{\left(K k_{B}\right)^{-1}}{k^{-1}}\left[E_{K}+\frac{\partial \ln k_{B}^{-1}}{\partial(1 / T)}\right]
$$

Since the efficiency of stirring is expected to increase with temperature, the terms $\partial \ln {k_{A}}^{-1} / \partial(1 / T)$ and $\partial \ln {k_{B}}^{-1} / \partial(1 / T)$ are positive. Eqs. (14) and (15) show that $E_{\mathrm{k}}$ is the average of three contributions (in brackets) weighed by positive factors $\left(k_{A}^{-1} / k^{-1}, \ldots\right)$ smaller than unity and whose sum is equal to one by virtue of Eq. (10).

\section{MATERIALS AND METHODS}

The radioactive europium cation, ${ }^{152} \mathrm{Eu}^{3+}$, was purchased from LEA-CERCA (France). It was extracted by two diamide extractants, DMDBTDMA and DMDOHEMA, provided by CEA Marcoule and synthesized by Panchim (France). The extractants were diluted in TPH (hydrogenated tetrapropylene, an industrial mixture of branched isomers of dodecane). The structures of the two molecules are shown in Figure 2.

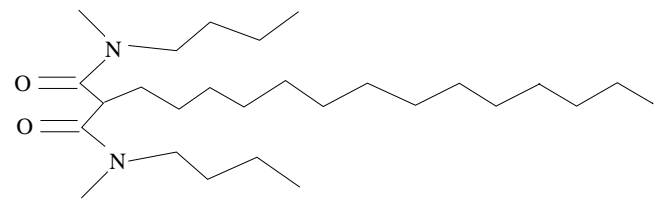

DMDBTDMA

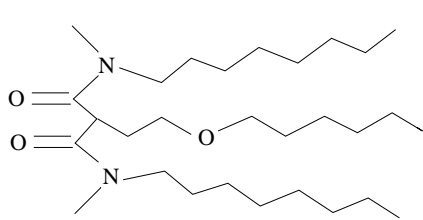

DMDOHEMA

Figure 2. Extractant molecules used in this study. 
The Durapore HVLP hydrophilic membrane (thickness $\approx 120 \mu \mathrm{m}$, measured porosity $\approx 71 \%$, pore size $\approx 0.45 \mu \mathrm{m}$ ) was purchased from Millipore ${ }^{\mathrm{TM}}$. The membranes were glued on the plastic cylinder with a mastic of polyurethane (Scotch Seal ${ }^{\mathrm{TM}} 5300$ ) purchased from 3M.

An aqueous solution of ${ }^{152} \mathrm{Eu}^{3+}$ was prepared by evaporating a drop of radioactive stock solution and then adding the suitable amount of nitric acid solution. An organic solution of ${ }^{152} \mathrm{Eu}^{3+}$ was obtained by equilibrating the latter aqueous solution with the organic extracting phase.

An extraction experiment is conducted as follows. First, the membrane is impregnated with the phase A containing the radiotracer. The surplus amount of solution is carefully removed by using a piece of paper towel impregnated with the same radioactive solution. Practice has shown that this operation can be performed reliably and reproducibly. In the case that $\mathrm{A}$ is an aqueous phase, a small drop of pure organic diluent is rapidly placed on top of the membrane in order to prevent evaporation. This precaution is not required in the case of a non-volatile organic phase. Then the cell is turned over, it is set into rotation at a known speed and, at $t=0$, it is plunged into the outer phase B. It is removed after a certain time and a sample of phase B is taken. Finally, the activity of this sample is counted in a radioactivity counter together with the activity of the cell bearing the membrane. The amount of extracted solute is deduced from these two activities.

\section{RESULTS AND DISCUSSION}

\section{Experiments with DMDBTDMA}

The extraction kinetics of $\mathrm{Eu}(\mathrm{III})$ from a $2 \mathrm{M} \mathrm{HNO}_{3}$ aqueous solution into an organic solution of 0.5 M DMDBTDMA in HTP were studied using the RMC technique at $600 \mathrm{rpm}$ and $22^{\circ} \mathrm{C}$. These concentrations were also employed in previous studies. ${ }^{[7,8]}$

The result is shown in Figure 3. 


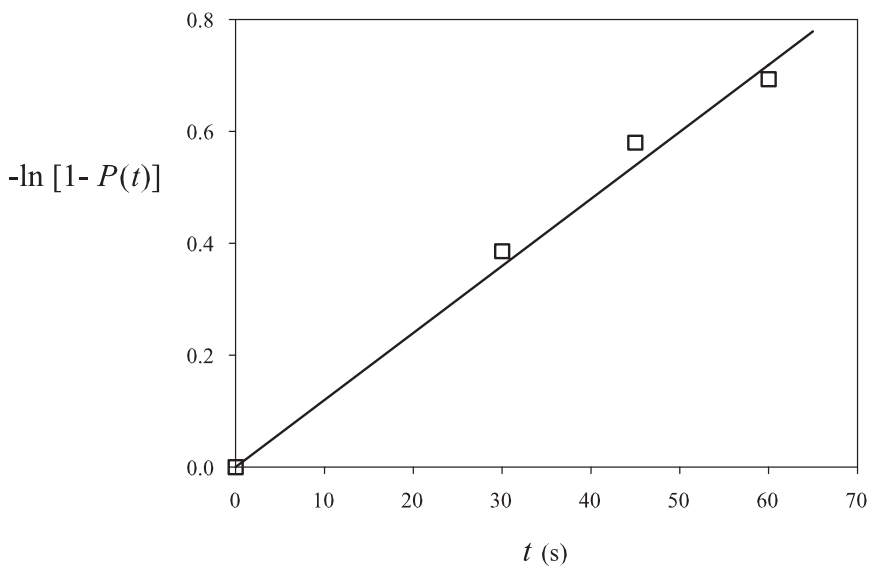

Figure 3. Extraction kinetics by DMDBTDMA: $(\square)$ experimental results, solid line = calculated diffusive limit (from Eqs. (11) and (12), see text)

The extraction process is seen to be rather fast, with an extraction rate of ca. $50 \%$ after $1 \mathrm{~min}$. The main result observed in Figure 3 is that the extraction is controlled by diffusion because the experimental points are located on the line corresponding to the diffusive limit given by $t / \tau_{\infty}$ (see Eqs. (11) and (12)), which is not a fit of the experimental points and involves no adjustable parameter. The value of $\tau_{\infty}$ was computed from the following measured parameter values (here $\mathrm{A}=\mathrm{aq}, \mathrm{B}=\mathrm{org}$ ): $L=112 \mu \mathrm{m}, D_{\mathrm{A}}=5.0 \times 10^{-6} \mathrm{~cm}^{2} \mathrm{~s}^{-1}, f=1.88, D_{\mathrm{B}}=4.1 \times 10^{-7} \mathrm{~cm}^{2} \mathrm{~s}^{-1}$, $\sigma=0.706, \mathrm{~K}=0.26, v_{\mathrm{org}}=4.43 \times 10^{-2} \mathrm{~cm}^{2} \mathrm{~s}^{-1}$. These data yield $\tau_{\mathrm{A}}=15.7 \mathrm{~s}$ and $\tau_{\mathrm{B}}=67.8 \mathrm{~s}$, so that $\tau_{\infty}=83.5 \mathrm{~s}$.

The present result is therefore in agreement with the observation made in ref. [8], and in contradiction with the result of ref. [7] which reported a slow interfacial reaction, with a kinetic rate constant $k_{f} \sim 7 \times 10^{-5} \mathrm{~cm} \mathrm{~s}^{-1}$.

The model proposed above to describe the diffusive contribution to mass transfer in a Lewistype cell may be applied to the system of this latter work. ${ }^{[7]}$ The velocity of the eddies, $V_{0}$, was of the order of a few $\mathrm{cm} \mathrm{s}^{-1}$ when the rotation speed of the stirring bars was typically 200 rpm, as observed by the first author of the present work in the set-up used by $\mathrm{V}$. Toulemonde, ${ }^{[5]}$ by introducing a dye in the upper (organic) phase. With the parameter values given in the previous paragraph, and taking $\alpha=1, V_{0}{ }^{\mathrm{aq}}=4 \mathrm{~cm} \mathrm{~s}^{-1}, V_{0}{ }^{\text {org }}=2 \mathrm{~cm} \mathrm{~s}^{-1}$ (smaller than in aqueous phase because of higher damping caused by the viscosity), it is found from Eq. (4) that the kinetic parameters of Eq. (5) have the following values: ${k_{D}}^{a q} \approx 3.34 \times 10^{-2} \mathrm{~cm} \mathrm{~s}^{-1}, K$ $k_{D}{ }^{\text {org }} \approx 8.8 \times 10^{-5} \mathrm{~cm} \mathrm{~s}^{-1}$. Thus Eq. (5) entails that ${k_{D}}^{\text {extr }} \approx K{k_{D}}^{\text {org }} \approx 8.8 \times 10^{-5} \mathrm{~cm} \mathrm{~s}^{-1}$ because the main resistance then originates from the convective transport in organic phase, because of the 
value of $K$, and of the smaller value of $D$ and higher viscosity for the organic phase versus the aqueous phase. We notice that this result for $k_{D}{ }^{\text {extr }}$ is in good agreement with the observed experimental value for the kinetic rate constant $k_{f} \sim 7 \times 10^{-5} \mathrm{~cm} \mathrm{~s}^{-1}$. However it must be recognized that it is at least partly fortuitous because it has been found by making several assumptions and approximations about the description of the turbulent flow (on the values of $\alpha$ and $V_{0}$ ). Therefore the relative uncertainty on the value of ${k_{D}}^{\text {extr }}$ from the model is large. Nevertheless, the accord of ${k_{D}}^{\text {extr }}$ with the value of $k_{f}$ found in ref. [7] strongly suggests that mass transfer was controlled by diffusive transport, not by the interfacial chemical reaction, in this experiment.

\section{Experiments with DMDOHEMA}

The kinetics of extraction of $\mathrm{Eu}(\mathrm{III})$ from $3 \mathrm{M}$ nitric acid solutions were investigated using the RMC technique at $11^{\circ} \mathrm{C}, 22^{\circ} \mathrm{C}$ and $33^{\circ} \mathrm{C}$, into organic solutions of $0.65 \mathrm{M}$ DMDOHEMA in HTP. These concentrations are typical of the envisaged DIAMEX process at industrial scale. Let us recall that, at each temperature, the organic phases were previously equilibrated with a pure $3 \mathrm{M} \mathrm{HNO}_{3}$ solution.

The diffusion coefficients of $\mathrm{Eu}(\mathrm{III})$ in these phases were measured using the closed capillary technique ${ }^{[17]}$ suitable for $\gamma$ emitters (the $\beta$ radiation being stopped by a glass capillary placed inside the scintillating plastic tube). The experimental result is the ratio $P_{\text {cap }}(t)=A(t) / A(0)$, with $A(t)$ the activity measured by the beta-counter (counting the number of photons created in the scintillating plastic). The theoretical expression for this ratio is: ${ }^{[17]}$

$$
P_{\text {cap }}(t)=0.602+0.377 \exp \left(-t / t_{\mathrm{D}}\right)+0.0156 \exp \left(-9 t / t_{\mathrm{D}}\right)+\ldots
$$

in which $t_{\mathrm{D}}=L_{0}{ }^{2} / \pi^{2} D$, and $L_{0}$ is the length of the glass capillary (typically, $L_{0}=3 \mathrm{~cm}$ ) and the factors are found from the geometric parameters of the diffusion cell.

The results for these measurements are collected in Table 1. The latter also reports the values of the hydrodynamic radius, $R_{\mathrm{org}}$, of the complex in organic phase, assessed from Stokes formula, $D_{\text {org }}=k T / 6 \pi \eta_{\text {org }} R_{\text {org }}$, with $\eta_{\text {org }}$ the dynamic viscosity $\left(=v_{\text {org }} d_{\text {org }}\right.$, in which $d_{\text {org }}$ is the density of the solvent). It is found to decrease slightly with temperature while the diffusion

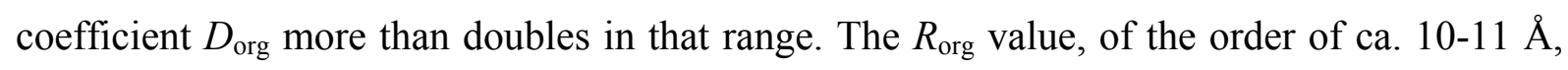
points to a big diffusing species in the organic phase. 
Table 1: Values of the transport parameters in both phases, of the hydrodynamic radius of complex in organic, of the distribution ratio, and of the extraction kinetic rate constant for the

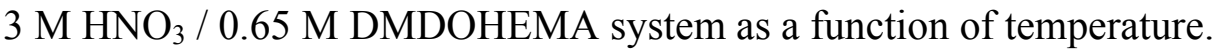

\begin{tabular}{|c|c|c|c|c|c|c|}
\hline$t\left({ }^{\circ} \mathrm{C}\right)$ & $\begin{array}{c}D_{\mathrm{aq}} \\
\left(10^{-6} \mathrm{~cm}^{2} \mathrm{~s}^{-1}\right)\end{array}$ & $\begin{array}{c}D_{\text {org }} \\
\left(10^{-6} \mathrm{~cm}^{2} \mathrm{~s}^{-1}\right)\end{array}$ & $\begin{array}{c}v_{\text {org }} \\
\left(\mathrm{cm}^{2} \mathrm{~s}^{-1}\right)^{[9]}\end{array}$ & $\begin{array}{c}R_{\text {org }} \\
(\AA)\end{array}$ & $\begin{array}{c}k_{f} \\
\left(10^{-3} \mathrm{~cm} \mathrm{~s}^{-1}\right)\end{array}$ \\
\hline 11 & 4.32 & 0.334 & 0.0654 & 11.4 & 5.45 & 1.20 \\
\hline 22 & 5.66 & 0.503 & 0.0483 & 10.7 & 3.12 & 5.58 \\
\hline 33 & 7.83 & 0.721 & 0.0375 & 9.71 & 1.65 & 20.9 \\
\hline
\end{tabular}

The experimental results for the diffusion coefficient of $\mathrm{Eu}(\mathrm{III})$ in pre-equilibrated organic phase at $11^{\circ} \mathrm{C}, 22^{\circ} \mathrm{C}$ and $33^{\circ} \mathrm{C}$ are shown in Figure 4. It is about 10 times smaller than the diffusion coefficient of $\mathrm{Eu}(\mathrm{III})$ in the aqueous phase.

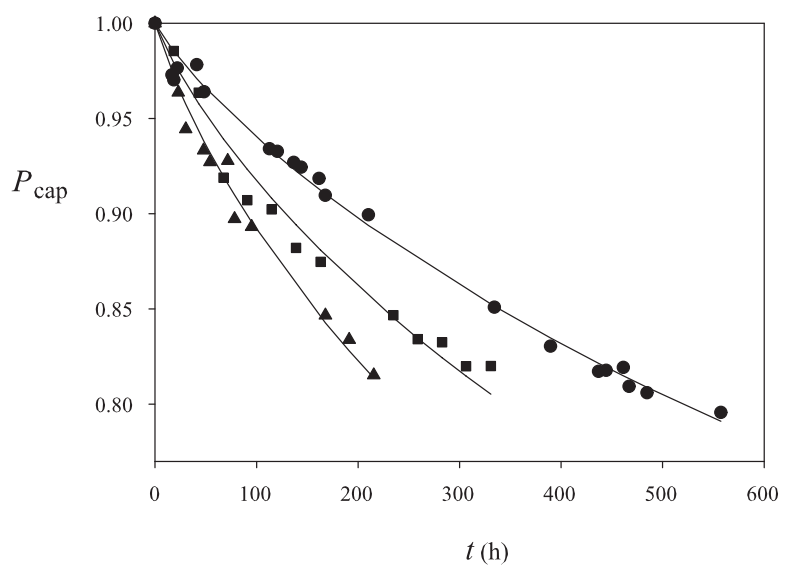

Figure 4. Experimental curves for $P_{\text {cap }}(t)$ at various temperatures: $(\bullet) 11^{\circ} \mathrm{C},(\boldsymbol{\square}) 22^{\circ} \mathrm{C},(\boldsymbol{\Delta}) 33^{\circ} \mathrm{C}$. Solid lines: results of fits of $D_{\text {org }}$ using Eq. (16).

Besides these measurements, the diffusion coefficient of the ${ }^{152} \mathrm{Eu}^{3+}$ tracer was measured in a pure $0.65 \mathrm{M}$ DMDOHEMA solution at $22^{\circ} \mathrm{C}$, that had not been previously equilibrated with an aqueous nitric acid solution. This phase was prepared by first evaporating a drop of radioactive solution of ${ }^{152} \mathrm{Eu}^{3+}$ in a tube. Then, $1 \mathrm{~mL}$ of organic phase was poured into the tube. After one day, this solution was used for a measurement of the diffusion coefficient. The result was $D_{\text {org }}=2.64 \times 10^{-6} \mathrm{~cm}^{2} \mathrm{~s}^{-1}$. Surprisingly, this value is more than 5 times larger than the value reported in Table 1 at $22^{\circ} \mathrm{C}$. This result shows that in this experiment the absence of water and nitric acid leads to a diffusing species of much smaller size in the organic phase, as compared to the case of a solution pre-equilibrated with the aqueous phase. The 
hydrodynamic radius of the species in this case is found to be $R_{\text {org }}=2.04 \AA$. This small size suggests that the 'molecule' $\mathrm{Eu}\left(\mathrm{NO}_{3}\right)_{3}$ is not complexed by DMDOHEMA when no water and acid are co-extracted. This conclusion is further supported by the low activity of the radioactive solution obtained in this case (low dissolution of the solute caused by the absence of complexation by the extractant).

The measurement of these parameter values allowed a determination of the extraction kinetic rate constant from experimental data obtained for the function $P(t)$. The results at the three studied temperatures are shown in Figure 5 and the values found for $k_{f}$ from a fit of $\tau$ and using Eqs. (7)-(9) and (12) are given in Table 1. It is seen that the extraction rate constant increases significantly with $T$, and that the uncertainty on this parameter increases accordingly because the extraction rate becomes closer to the diffusive limit as the temperature is increased (see Figure 5). The extraction process with DMDOHEMA is slower than with DMDBTDMA at $22^{\circ} \mathrm{C}$, but it also becomes diffusion controlled at $33^{\circ} \mathrm{C}$ as shown in Figure 5, with the experimental points close to the diffusive limit (dashed line).

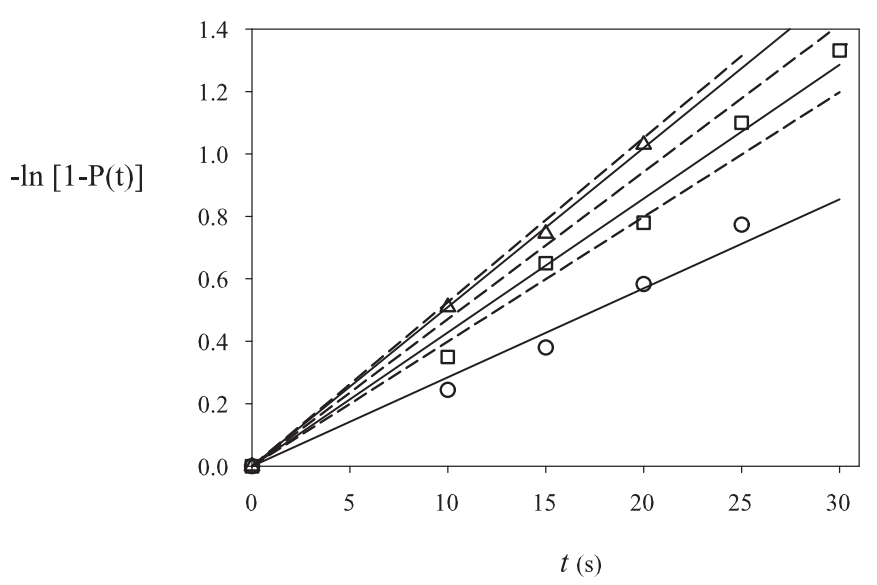

Figure 5. Experimental results for $-\ln [1-P(t)]$ at various temperatures: (O) $11^{\circ} \mathrm{C},(\square) 22^{\circ} \mathrm{C},(\triangle) 33^{\circ} \mathrm{C}$. Solid lines (bottom line $=11^{\circ} \mathrm{C}$, top $=33^{\circ} \mathrm{C}$ ): results of fits using Eq. (12); Dashed lines: diffusive limits obtained from Eq. (11) (bottom line $=11^{\circ} \mathrm{C}$, top $\left.=33^{\circ} \mathrm{C}\right)$ ).

The activation energy, $E_{\mathrm{f}}$, for the rate constant $k_{f}$ was determined from Table 1 . The values of $\ln \left[k_{f}(T) / k_{f}\left(T_{0}\right)\right]$ with $T_{0}=295.15 \mathrm{~K}\left(=22^{\circ} \mathrm{C}\right)$, are plotted in Figure 6 together with the similar plots for the parameters $D_{\mathrm{aq}}, D_{\mathrm{org}}, v_{\mathrm{org}}$ and $K$. From these plots one gets $E_{k f} \approx 94.0 \mathrm{~kJ} \mathrm{~mol}^{-1}$, $E_{\text {Daq }} \approx 19.5 \mathrm{~kJ} \mathrm{~mol}^{-1}, E_{\text {Dorg }} \approx 25.3 \mathrm{~kJ} \mathrm{~mol}^{-1}, E_{\mathrm{vorg}} \approx-18.3 \mathrm{~kJ} \mathrm{~mol}^{-1}, E_{K} \approx-39.2 \mathrm{~kJ} \mathrm{~mol}^{-1}$, respectively. The activation energies of the diffusion coefficients are both of the order of 20 $\mathrm{kJ} \mathrm{mol}^{-1}$, as for small ions like $\mathrm{Na}^{+}$and $\mathrm{Cl}^{-}$in water between 0 and $50^{\circ} \mathrm{C}$ (results not shown). 


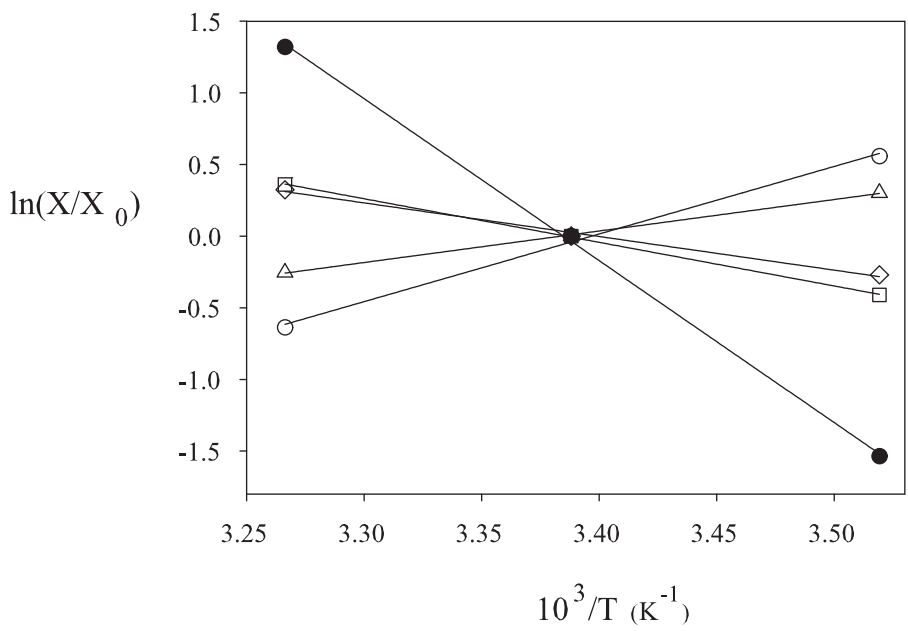

Figure 6. Plot of $\ln \left(X(T) / X\left(T_{0}\right)\right)$ vs. $10^{3} / T$ for $X=k_{f}(\bullet), D_{\text {aq }}(\diamond), D_{\text {org }}(\square), v_{\text {org }}(\triangle), K(\bigcirc)$.

A particular feature noticed in Table 1 is that the distribution ratio decreases with temperature, thus making the associated activation energy negative. The viscosity of the organic phase also decreases with $T$, but as seen in Eq. (14) it contributes positively to the activation energy of the global apparent rate constant, $k$.

The numerical value of $E_{k}$ found from the results for these activation energies and Eq. (14) is $E_{k} \approx 17.6 \mathrm{~kJ} \mathrm{~mol}^{-1}$. This is a rather low value, typical of a diffusion controlled process, which is nearly the case here at $22^{\circ} \mathrm{C}$ (see Figure 5). It is observed in Eq. (14) that the contribution from $E_{\mathrm{K}}$ more than compensates the contribution from $E_{k f}\left(-8.85 \mathrm{~kJ} \mathrm{~mol}^{-1}\right.$ and $+8.65 \mathrm{~kJ} \mathrm{~mol}^{-1}$, respectively).

The general case may also be discussed on the basis of Eq. (15). The latter relation shows that the activation energy for the apparent rate constant $k$ can be low not only in the case of diffusion controlled processes or interfacial chemical reactions of low activation energy. ${ }^{[14]}$ It can also be low if $K$ is not large, so that the last term in Eq. (15) contributes significantly, and if the activation energy of $K$ is sufficiently negative and large in absolute value. In such a case, the activation energy $E_{k}$ may erroneously point to a diffusion controlled process. In the extreme case, it may be put forward that $E_{\mathrm{k}}$ could even become negative if $K$ decreases rapidly with temperature and if the process is controlled by transport in phase B. However, we are not aware of such an observation in the literature.

This discussion brings further support to the contention that the raw value of the activation energy of the global kinetic rate constant is not a reliable indicator of the extraction regime. 


\section{CONCLUSION}

The extraction kinetics of europium(III) cation by DMDBTDMA at $22^{\circ} \mathrm{C}$ seems to be very fast and the process seems to be controlled by diffusion. The slow interfacial reaction kinetics reported in the literature using a Lewis-type cell might well have been caused by the effect of a remaining diffusion layer in the organic phase.

The kinetics of extraction by DMDOHEMA is found to be slower than by the former extractant at $22^{\circ} \mathrm{C}$, but it accelerates rapidly with temperature and becomes fast at $33^{\circ} \mathrm{C}$.

In the case that the distribution ratio decreases with temperature, the effect of its activation energy is to lower that of the global rate constant because it brings a negative contribution. In subsequent work, we will present results for experiments aimed at a better control of the DIAMEX-SANEX process. The extraction solvent will be composed of mixtures of DMDOHEMA and HDEHP, or of mixtures of TODGA and TBP.

\section{ACKNOWLEDGEMENTS}

This work was supported by a grant from GNR Paris. We acknowledge interesting discussions with Laurence Berthon from CEA Marcoule. The extractant molecules were kindly provided by CEA Marcoule. 


\section{REFERENCES}

1. Camès, B.; Bisel, I.; Baron, P.; Hill, C.; Rudloff, D.; Saucerotte, B. DIAMEX Solvent Behavior under Continuous Degradation and Regeneration Operations, in Nuclear Energy and the Environment, Wai C. et al., ACS Symposium Series, American Chemical Society: Washington DC, 2010, vol. 1046, pp. 255-269.

2. Cuillerdier C.; Musikas C.; Hoel, P.; Nigond, L.; Vitart, X. Malonamides as New Extractants for Nuclear Waste Solutions, Sep. Sci. Technol. 1991, 26, 1229-1244.

3. Serrano-Purroy, D.; Christiansen, B.; Glatz, J.P.; Malmbeck, R.; Modolo, G. Towards a DIAMEX process using high active concentrate. Production of genuine solutions, Radiochim. Acta 2005, 93, 357-361.

4. Baron, P.; Hérès, X.; Lecomte, M.; Masson, M. Separation of the minor actinides: the DIAMEX-SANEX concept. Proc. Global 2001, Paris, France, September 9-13.

5. Toulemonde, V. Cinétique d'extraction liquide-liquide du nitrate d'uranyle et des nitrates d'actinides (III) et des lanthanides (III) par des extractants à fonction amide, PhD thesis, Université Paris 6, 1995.

6. Dal Don, M. Etude des cinétiques d'extraction des nitrates de lanthanides (III) et d'actinides (III) par le diamide DMDBTDMA, $\mathrm{PhD}$ thesis, Université Paris 11, 1997.

7. Charbonnel, M.C.; Dal Don, M.; Berthon, C.; Presson, M.T.; Madic, C.; Moulin, C., Extraction of Lanthanides(III) and Actinides(III) by N,N'-Substituted Malonamides: Thermodynamic and Kinetic Data, Proceedings of ISEC'99, Barcelona, Spain, 1999, Elsevier: Amsterdam, 2000, pp. 1333-1338.

8. Weigl, M.; Geist, A.; Gompper, K.; Kim, J.I. Kinetics of Lanthanide/Actinide Coextraction with N,N'-Dimethyl-N,N'-Dibutyltetradecylmalonic Diamide (DMDBTDMA), Solvent Extr. Ion Exch. 2001, 19, 215-229.

9. Bosland, L. Etude thermodynamique et cinétique de l'extraction des nitrates de lanthanides par un malonamide. $\mathrm{PhD}$ thesis, Université Paris 6, 2005.

10. Geist, A.; Hill, C.; Modolo, G.; Foreman, M.; Weigl, M.; Gompper, K.; Hudson, M. $6,6^{\prime}$ - Bis $(5,5,8,8$ - tetramethyl - 5,6,7,8 - tetrahydro - benzo[1,2,4] triazin - 3 - yl) [2,2']-bipyridine, an Effective Extracting Agent for the Separation of Americium(III) and Curium(III) from the Lanthanides, Solvent Extr. Ion Exch. 2006, 24, 463-483.

11. Tarasov, V. V.; Kizim, N. F.; Yagodin, G. A. Kinetics of Extraction and Re-extraction During a Brief Contact between the Phases. Russ. J. Phys. Chem. 1971, 45, 14251428.

12. Albery, W. J.; Burke, J. F.; Leffler, E. B.; Hadgraft, J. J. Interfacial Transfer Studied with a Rotating Diffusion Cell, J. Chem. Soc. Faraday Trans. 1976, 72, 1618-1626.

13. Durand-Vidal, S.; Simonin, J.P.; Turq, P. Electrolytes at Interfaces, Kluwer: Dordrecht, 2000.

14. Danesi, P. R., Chapter 5, Solvent Extraction Kinetics, in Solvent Extraction Principles and Practice, Rydberg, J.; Cox, M.; Musikas, C.; Choppin, G.R. Eds.; Marcel Dekker: New York, 2004, pp. 203-251.

15. Levich, V. G. Physicochemical Hydrodynamics, Prentice Hall: Englewood Cliffs, 1962.

16. Lewis, F.; Harwood, L.M.; Hudson, M.J.; Drew, M.G.B.; Desreux, J.F.; Vidick, G. ; Bouslimani, N.; Modolo, G.; Wilden, A.; Sypula, M.; Vu, T.H.; Simonin, J.P. Highly Efficient Separation of Actinides from Lanthanides by a Phenanthroline-Derived Bis-Triazine Ligand, J. Am. Chem. Soc. 2011, 133, 13093-13102. 
17. Simonin, J. P.; Mills, R.; Perera, A.; Turq, P.; Tallet, F. Closed Capillary Method for the Diffusion of Biological Macromolecules, J. Solution Chem. 1986, 15, 1015-1030.

18. Simonin, J. P.; Weill, J., Rotating Membrane Cell technique for the Study of Liquid/liquid Extraction Kinetics, Solv. Extr. Ion Exch. 1998, 16, 1493- 1514.

19. Simonin, J. P.; Hendrawan, H. Effect of a Salt on the Kinetics of Solute Transfer at a Free Liquid/Liquid Interface, J. Phys. Chem. B 2000, 104, 7163-7170. 